\title{
Severe hypercalcemia caused by parathyroid hormone in a rectal cancer metastasis: a case report
}

\author{
Vegard Heimly Brun ${ }^{1,2^{*}}$, Erik Knutsen ${ }^{2}$, Helge Stenvold ${ }^{3}$ and Hanne Halvorsen ${ }^{4}$
}

\begin{abstract}
Background: Hypercalcemia of malignancy is relatively common in several cancers. However, in colorectal cancer, paraneoplastic phenomena that cause hypercalcemia is uncommon. In the few cases that are reported, secretion of parathyroid hormone-related peptide mediates the effect. We describe the first case of severe hypercalcemia mediated by intact parathyroid hormone secretion from a bone metastasis of colorectal origin. This was a diagnostic and therapeutic challenge.

Case presentation: A 68-year-old male treated for rectal adenocarcinoma 10 years earlier developed a bone metastasis. After initial treatment of the metastasis with surgery and irradiation, he developed a relapse with severe hypercalcemia and corresponding elevated parathyroid hormone levels. The workup showed no signs of parathyroid adenomas, but the metastasis produced intact parathyroid hormone. The hypercalcemia was successfully treated by irradiation and osteoclast inhibitor, and the patient received chemotherapy. Survival was 24 months from the onset of hypercalcemia.
\end{abstract}

Conclusions: Proper diagnosis of the uncommon endocrine disturbance allowed targeted therapy and avoidance of neck exploration for wrongly suspecting primary hyperparathyroidism. Intact parathyroid hormone should be measured in cases of malignant hypercalcemia.

Keywords: Parathyroid hormone, Hypercalcemia, Colorectal cancer, Metastasis, Case report

\section{Background}

Hypercalcemia of malignancy occurs in approximately $20-30 \%$ of all cancers [1], and is associated with poor prognosis. Thirty-day-mortality in cancer-related hypercalcemia can be as high as $50 \%$ [2]. Medical treatment may require hospitalization and have severe side effects [3]. Although the underlying cause can be osteolytic metastases, hypercalcemia of malignancy is usually caused by secretion of an active peptide such as parathyroid

\footnotetext{
* Correspondence: vegardbrun@gmail.com; vegard.heimly.brun@unn.no 'Department of Breast- and Endocrine Surgery, University Hospital of North Norway, Sykehusvegen 38, 9019 Troms $\varnothing$, Norway

${ }^{2}$ UiT The Arctic University of Norway, Faculty of Health Sciences, Hansine Hansens veg 18, 9019 Tromsø, Norway

Full list of author information is available at the end of the article
}

hormone-related peptide (PTHrP), parathyroid hormone $(\mathrm{PTH})$ or calcitriol $[4,5]$. Secretion of PTHrP or ectopic PTH has been described in neuroendocrine tumors and a range of carcinomas, leukemia, lymphoma and rhabdomyosarcoma. The carcinomas known to cause these endocrine paraneoplastic effects are squamous cell, renal, bladder, breast, ovary, lung, thyroid, neuroectodermal and pancreatic carcinomas. Hypercalcemia in colorectal adenocarcinomas is rare, and it is usually caused by secretion of PTHrP. To our knowledge, this is the first report of intact $\mathrm{PTH}$ production from a colorectal bone metastasis.

C C The Author(s). 2021 Open Access This article is licensed under a Creative Commons Attribution 4.0 International License, which permits use, sharing, adaptation, distribution and reproduction in any medium or format, as long as you give appropriate credit to the original author(s) and the source, provide a link to the Creative Commons licence, and indicate if changes were made. The images or other third party material in this article are included in the article's Creative Commons licence, unless indicated otherwise in a credit line to the material. If material is not included in the article's Creative Commons licence and your intended use is not permitted by statutory regulation or exceeds the permitted use, you will need to obtain permission directly from the copyright holder. To view a copy of this licence, visit http://creativecommons.org/licenses/by/4.0/ The Creative Commons Public Domain Dedication waiver (http://creativecommons.org/publicdomain/zero/1.0/) applies to the data made available in this article, unless otherwise stated in a credit line to the data. 


\section{Case presentation}

A 68 years old male had undergone total mesorectal excision 10 years before a skeletal metastasis of the lower leg was diagnosed. The patient was otherwise healthy except mild hypertension and there was no familial accumulation of endocrine or malignant diseases. Histology from the primary surgery showed a 5 $\mathrm{cm}$ intermediately differentiated adenocarcinoma of the rectum with no signs of neuroendocrine biology. The tumor was CK7 negative and CK20 positive. Distance to the nearest circumferential margin was 3 $\mathrm{mm}$, and end resection margins were clear. There was no infiltration in the removed lymph nodes nor signs of distant metastases, thus the final TNM status was pT3N0M0. Total calcium was normal $(2.37 \mathrm{mmol} / \mathrm{L})$. Carcinoembryonic antigen (CEA) dropped from $18.0 \mu \mathrm{g} / \mathrm{L}$ preoperatively to $1.5 \mu \mathrm{g} / \mathrm{L}$ after surgery. No neo-adjuvant or adjuvant radiochemotherapy was given during the primary treatment. He underwent standard follow-up regimen with bloodwork, rectoscopies, ultrasound of the liver and chest $\mathrm{x}$-ray for 4 years without any signs of relapse. CEA values were stable under $2.0 \mu \mathrm{g} / \mathrm{L}$ and only $1.0 \mu \mathrm{g} / \mathrm{L}$ when followup was completed.

Ten years after surgery, the patient presented with a tumor in the lower leg. X-ray and magnetic resonance imaging showed a $4.4 \mathrm{~cm}$ osteolytic lesion of the fibular head, in addition to a $4.7 \mathrm{~cm}$ tumor in the left lung and paratracheal pathological lymph nodes. Biopsies of the fibular head confirmed adenocarcinoma negative for CK7 and positive for CK20, and the pathologist concluded metastasis from the rectal cancer. The histological pattern was similar to the previously resected rectal tumor (Fig. 1). CEA had now increased to $15.4 \mu \mathrm{g} / \mathrm{L}$. He was treated by radiation therapy to the leg $(8 \mathrm{~Gy} \times 1)$ and commenced chemotherapy (fluorouracil, irinotecan, calcium folinate and bevacizumab). His lung pathology stabilized during this treatment and he reported less pain from the leg after the radiation therapy. However, the fibular tumor progressed radiologically and was $7 \mathrm{~cm}$ in diameter when it was resected 15 months after discovery. Resection margins were uncertain, and he developed a wound infection with a chronic fistula to the skin.

Three months later, the patient presented with hypercalcemia after being normocalcemic during all previous follow-up. Due to rapidly growing inguinal and retroperitoneal lymph nodes, he started treatment with fluorouracil, leucovorin, and oxaliplatin (FLOX). CT-scan showed stable disease after three cycles of therapy. Bloodwork revealed that CEA had increased markedly to $380 \mu \mathrm{g} / \mathrm{L}$. He developed severe hypercalcemia with free ionized calcium reaching $1.81 \mathrm{mmol} / \mathrm{L}$
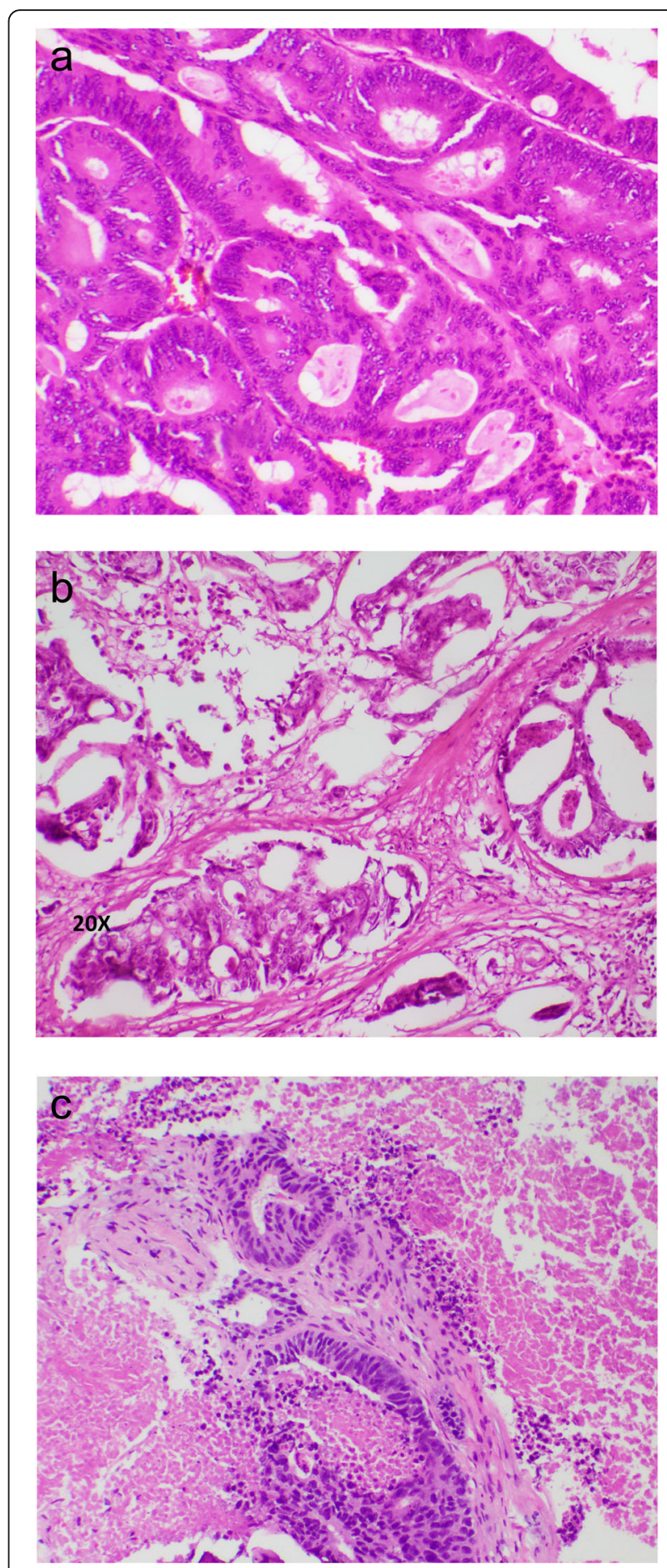

Fig. 1 Hematoxylin and eosin staining showed architecture typical for adenocarcinoma. Representative sample form the rectal resection (a), resection of fibula head (b), and from the fibula biopsy taken after onset of hypercalcemia (c)

(total calcium $3.33 \mathrm{mmol} / \mathrm{L}$ ), concurrent with peaks in CEA and PTH levels (Fig. 2). Creatinine and estimated GFR was normal, phosphorus was low $(0.62$ 


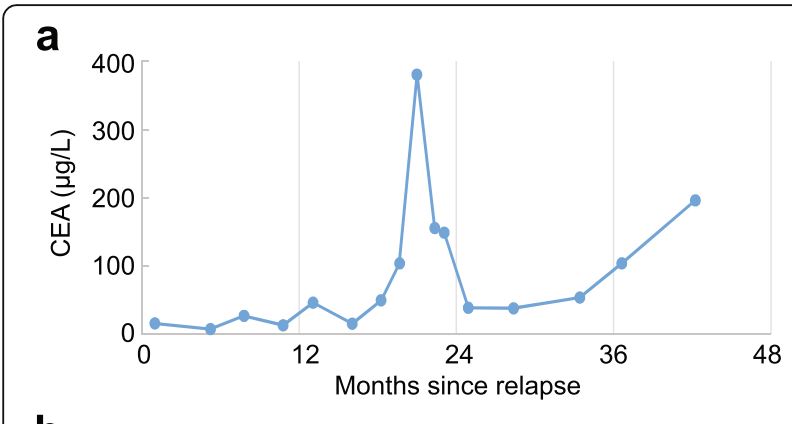

b

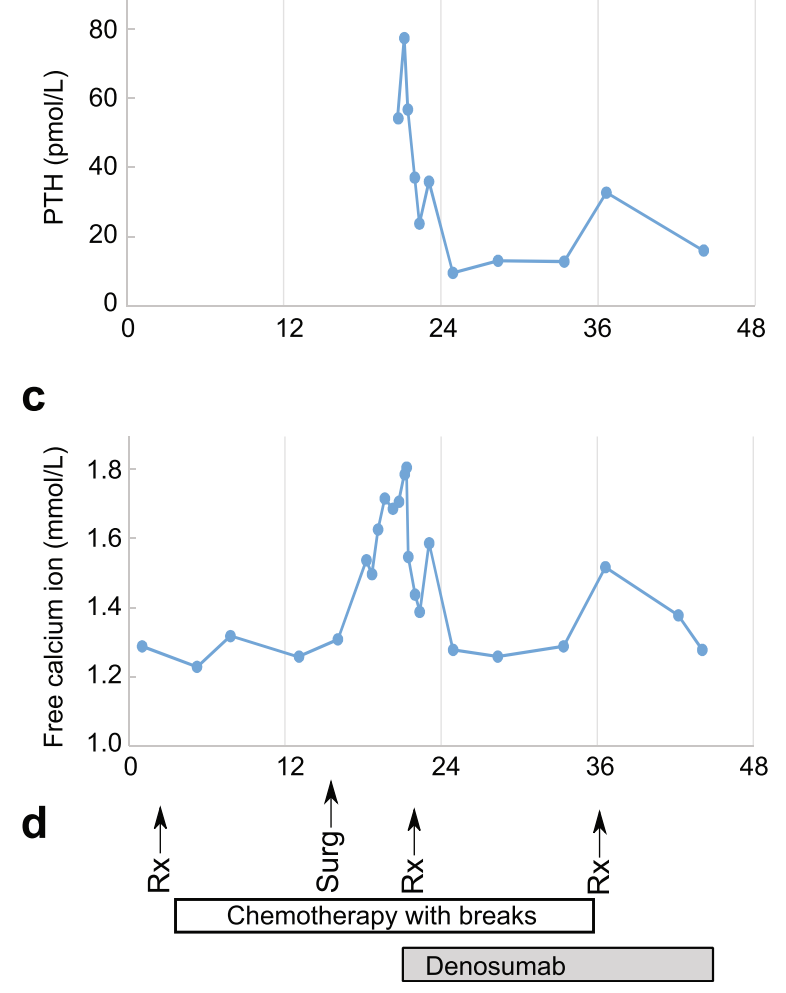

Fig. 2 Levels of carcinoembryonic antigen (CEA, a), parathyroid hormone $(\mathrm{PTH}, \mathbf{b})$ and free calcium (c) after diagnosing rectal cancer relapse. $\mathbf{d}$ Outline of main treatment events. Rx: radiotherapy towards the fibula. Surg: Surgical resection of the fibular head

$\mathrm{mmol} / \mathrm{L}$ ), and 1,25-dihydroxyvitamin $\mathrm{D}$ was low (24 nmol/L). He had no arrhythmias or other clinical symptoms related to the hypercalcemia. Fluid therapy and zoledronic acid had only short-lasting effect on the calcium levels. PTHrP was negative, but intact $\mathrm{PTH}$ was elevated to $54.4 \mathrm{pmol} / \mathrm{L}$ (normal range 1.1$7.5 \mathrm{pmol} / \mathrm{L})$. The lab used a standard two-site immunoassay for measurement of the 84 amino acid long $\mathrm{PTH}$, requiring binding in both the $\mathrm{N}$ and $\mathrm{C}$ terminals for detection. The high PTH led us to consider primary hyperparathyroidism as a differential diagnosis. Ultrasound of the neck and parathyroid scintigraphy with $900 \mathrm{MBq}$ of $99 \mathrm{mTc}$ methoxyisobutylisonitrile (MIBI) showed no signs of parathyroid adenomas. The diagnostic challenge was to distinguish primary hyperparathyroidism from ectopic PTH production in a colorectal bone metastasis or potentially another tumor.

To investigate if the tumor of the fibular head was responsible for the PTH elevation, we biopsied the tumor and stained for PTH. No significant staining was observed, using monoclonal antibody immunohistochemistry. Because such a large tumor can contain different clones of cells, a negative biopsy does not rule out that PTH could be produced from a part of the tumor not represented in the biopsy. Also, PTH immunohistochemistry on bone biopsies could be false negative for unknown technical reasons. We therefore measured blood PTH levels while excluding the lower right leg from the circulation by use of a blood pressure cuff on the thigh (modified Casanova test [6], Fig. 3a). PTH levels measured in blood samples from the arm fell rapidly during the $20 \mathrm{~min}$ of right leg ischemia, consistent with local PTH production from the fibular tumor (Fig. 3b).

We concluded that the diagnosis was hypercalcemia caused by PTH secretion from the bone metastasis in the fibular head, and focused further treatment against the fibular tumor. The osteoclast inhibitor denosumab $120 \mathrm{mg}$ was administered subcutaneously and further radiotherapy was given to the lower leg $(3 \mathrm{~Gy} \times 10)$. This made free calcium level stabilize at values around $1.40 \mathrm{mmol} / \mathrm{L}$, and PTH was also attenuated (Fig. 2). The patient received further cycles with FLIRI/bevacizumab until a year before his death. Six months before the patient died, another surge in PTH and calcium levels arose. Now, the patient received another course of radiotherapy $(4 \mathrm{~Gy} \times 5)$ towards his fibula, followed by a drop in PTH levels and normalization of calcium levels. No adverse events or side effects were reported by the patients or treating clinicians. The patient did not develop further episodes of severe hypercalcemia during the remainder of his life and died approximately 24 months after the first incident of severe hypercalcemia, due to disseminated disease involving skin, lymph nodes, lung, pancreas and brain.

As immunohistochemistry failed to show PTH in the fibular bone metastasis, we analyzed messenger ribonucleic acid (mRNA) from the same biopsies post mortem. Despite the long interval from biopsy to RNA extraction (5-16 years), we were able to extract total RNA from formalin-fixed paraffine embedded (FFPE) tissue sections and quantified PTH by reverse transcriptase quantitative polymerase chain reaction 

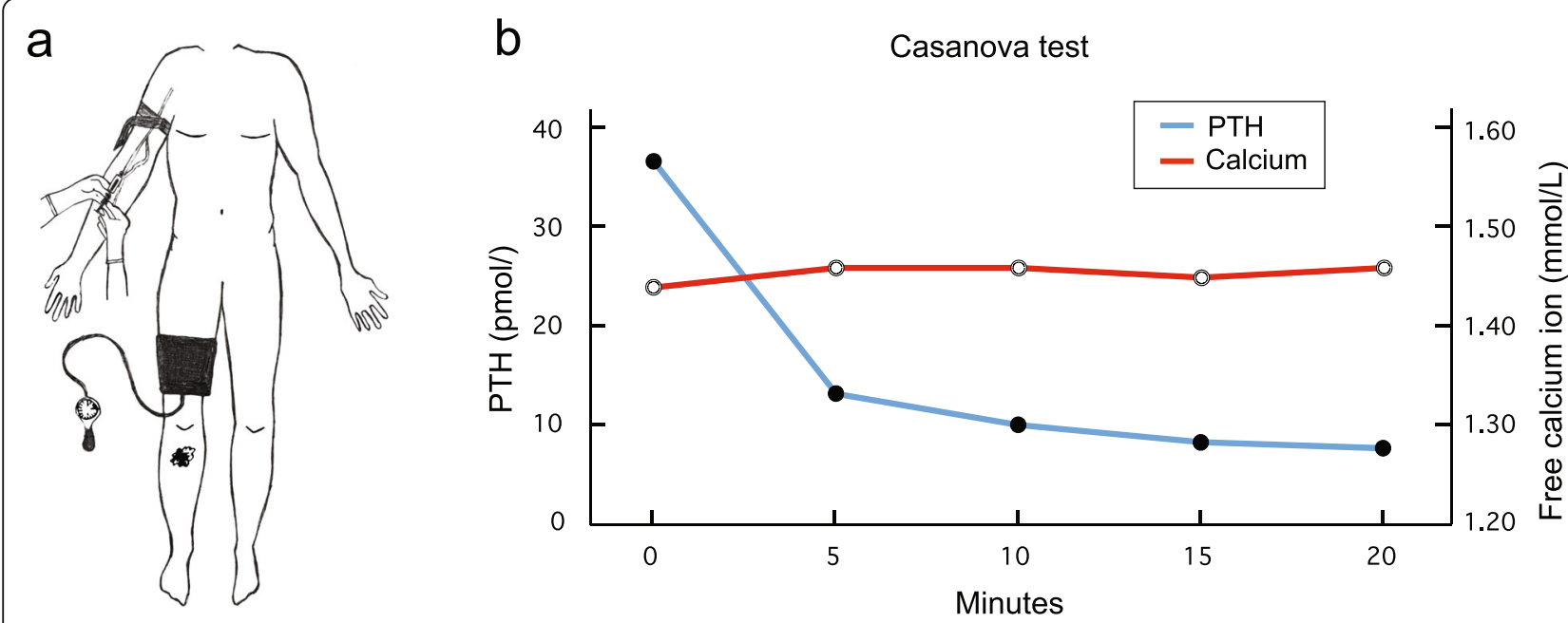

Fig. 3 Modified Casanova test to determine the source of PTH secretion. a A blood pressure cuff excluded the bone metastasis in the right fibula from circulation while systemic PTH and calcium levels were measured every 5 min. b A marked drop in PTH (blue line) during the 20 min ischemia confirmed PTH production in the right lower leg

(RT-qPCR $)^{1}$. We found evidence of $P T H$ transcription in both the original rectal specimen and in the fibular biopsy taken after onset of hypercalcemia, but not in the fibular biopsy that was taken before onset of hypercalcemia, nor in ipsilateral inguinal lymph node metastasis (Fig. 4). This is consistent with development of clinically significant PTH production within the fibular metastasis, after local recurrence and radiation therapy to the lower leg.

\section{Discussion and conclusion}

The case report is, to our knowledge, the first to describe production of intact PTH in a bone metastasis from rectal adenocarcinoma. The case illustrates the diagnostic and therapeutic challenges, and describes a

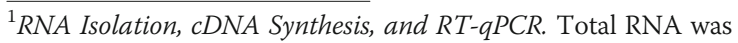
isolated from FFPE tissue sections using the High Pure FFPE tissue RNA Isolation kit (Roche) according to the manufacturer's recommendation. RNA concentration was measured by Qubit (Thermo Fisher Scientific). Complementary deoxyribonucleic acid (cDNA) synthesis of total RNA was performed with SuperScript ${ }^{\mathrm{Tu}}$ IV Reverse Transcriptase (ThermoFisher Scientific). $2.5 \mu \mathrm{M}$ of random hexamer primer (ThermoFisher Scientific) and approximately $80 \mathrm{ng}$ of template were used for the reaction. Total RNA was denaturated at $65^{\circ} \mathrm{C}$ for $5 \mathrm{~min}$, and cDNA was synthesized at $53^{\circ} \mathrm{C}$ for $10 \mathrm{~min}$. For real-time quantitative polymerase chain reaction (RT-qPCR), cDNA was mixed with FastStart Essential DNA Green Master (Roche Life Science) and $0.25 \mu \mathrm{M}$ forward and reverse primer. All primer sequences are provided in Supplementary Table 1. The LightCycler ${ }^{\circ} 96$ was used for quantification, and the $\Delta \Delta$ Cq-method was used to calculate fold change using the geometric mean of housekeeping genes (GAPDH and RPLPO) as internal reference.

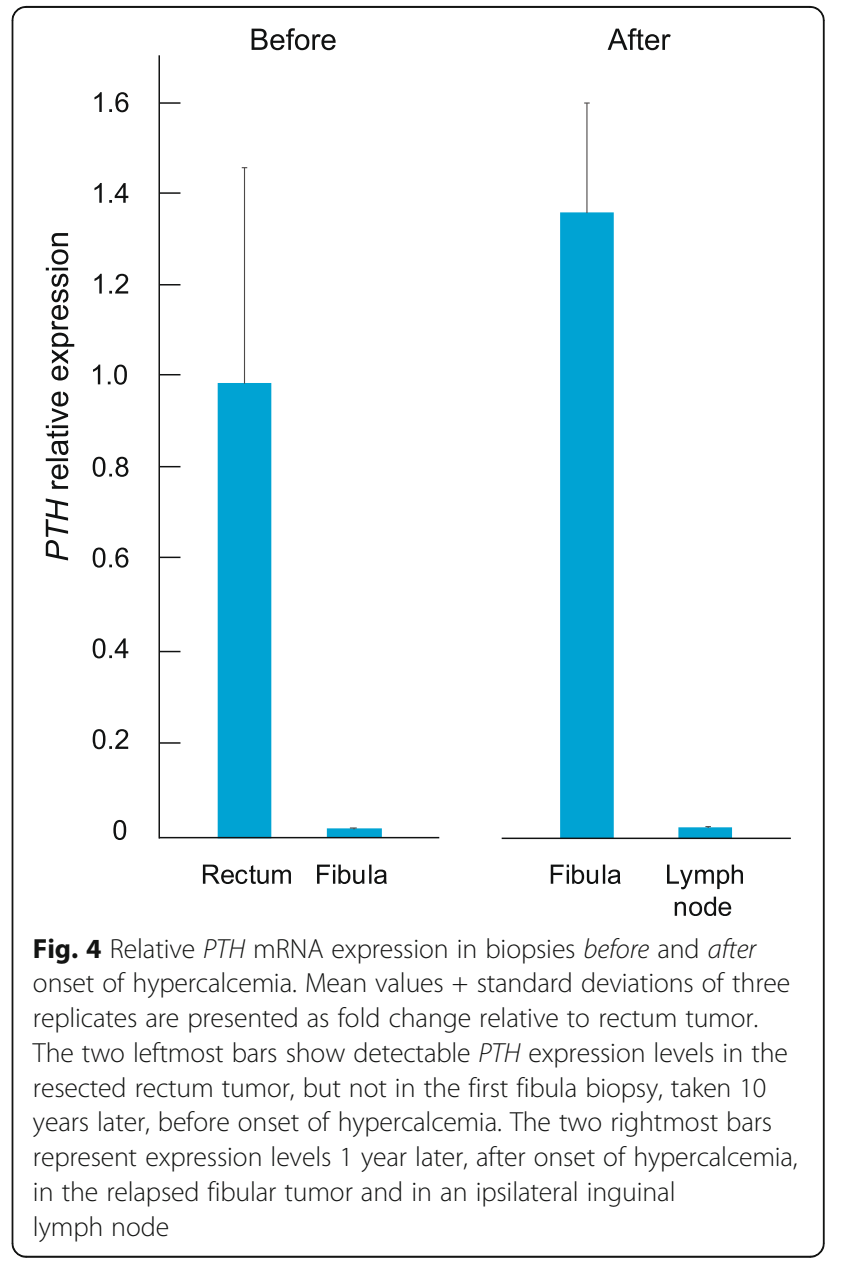


multimodal treatment during the relatively long survival of 24 months from the diagnosis of severe hypercalcemia. A review of malignant hypercalcemia in colorectal cancer described 29 cases with elevated PTHrP secretion [7], but none had hypersecretion of intact PTH. On the contrary, PTH levels are usually suppressed as a consequence of the hypercalcemia. PTHrP secretion is more common in tumors with neuroendocrine differentiation [8], but we did not find signs of neuroendocrine differentiation in the specimens examined from our patient.

In our case, the evidence that PTH secretion was indeed from the metastasis and not from a parathyroid adenoma or hyperplasia, are the modified Casanova test and post mortem measurements of PTH mRNA levels in biopsies. The systemic PTH level dropped when the blood circulation to the lower leg was excluded for 20 min. We could not demonstrate PTH production in the tumor by immunohistochemistry, however, the biopsy from the fibular metastasis had high expression of $P T H$ mRNA. We did not find evidence of other alternative PTH producing tumors in the lower leg on computer tomography scans, FDG-PET/CT scan or ultrasound scans that were made shortly after onset of hypercalcemia.

It is tempting to speculate that the irradiation therapy that was administered shortly after the relapse induced a transformation of the tumor cells to produce PTH, although there was a $>1$ year interval between radiation and hypercalcemia. Such transformation is not reported previously for adenocarcinomas, but the potential for radiation to induce malignant transformations is well-known $[9,10]$. More likely, the treatment could have led to selection of sub-clones with neuroendocrine properties, as the original rectal tumor showed evidence of PTH transcription. We did not see obvious transformation or dedifferentiation of the tumor cells upon examination and re-examination of all histological specimens. The pathological reports were consistent with primary rectal adenocarcinoma with similar morphology in the fibula specimen and biopsies.

To conclude, hypercalcemia of malignancy is relatively common in general, but rare in colorectal cancer. PTH should be measured in addition to PTHrP and calcitriol in these cases to allow tailored treatment. The differential diagnosis of primary hyperparathyroidism should be considered.

\section{Supplementary Information}

The online version contains supplementary material available at https://doi. org/10.1186/s12902-020-00664-8.

Additional file 1.

\section{Abbreviations}

PTH: Parathyroid hormone; PTHrP: Parathyroid hormone-related peptide; FLOX: Fluorouracil, leucovorin, oxaliplatin; FLIRI: Fluorouracil, folinic acid, irinotecan; CEA: Carcinoembryonic antigen; TNM: Tumor, nodes, metastasis; FDG-PET: Fluorodeoxyglucose positron emission tomography;

FFPE: Formalin-fixed paraffin embedded; mRNA: Messenger ribonucleic acid; cDNA: Complementary deoxyribonucleic acid; RT-qPCR: Real-time

quantitative polymerase chain reaction

\section{Acknowledgements}

We would like to thank Ingvild E. Nygård for artwork in Fig. 2 and Kristin

Åberg for help with RNA extraction.

\section{Authors' contributions}

VHB wrote the manuscript. VHB, $\mathrm{HS}$ and $\mathrm{HH}$ collected data and performed diagnostics. HS carried out oncological treatment. HH made the histology. EK performed the mRNA experiments and analysis. The authors read and approved the final manuscript.

\section{Funding}

This research did not receive any specific grant from any funding agency in the public, commercial or not-for-profit sector. The publication charges for this article have been funded by a grant from the publication fund of UiT

The Arctic University of Norway.

Availability of data and materials

Not applicable.

Ethics approval and consent to participate

Not applicable.

Consent for publication

Written informed consent was obtained from the patient's next of kin for publication of this Case Report and accompanying figures. A copy of the written consent is available for review by the Editor of this journal.

\section{Competing interests}

The authors declare no competing interests.

\section{Author details}

${ }^{1}$ Department of Breast- and Endocrine Surgery, University Hospital of North Norway, Sykehusvegen 38, 9019 Troms $\varnothing$, Norway. ${ }^{2} U i T$ The Arctic University of Norway, Faculty of Health Sciences, Hansine Hansens veg 18, 9019 Tromsø, Norway. ${ }^{3}$ Department of Oncology, University Hospital of North Norway, Sykehusvegen 38, 9019 Tromsø, Norway. ${ }^{4}$ Department of Clinical Pathology, University Hospital of North Norway, Sykehusvegen 38, 9019 Tromsø, Norway.

Received: 21 April 2020 Accepted: 9 December 2020

Published online: 07 January 2021

\section{References}

1. Stewart AF. Clinical practice. Hypercalcemia associated with cancer. N Engl J Med. 2005;352(4):373-9.

2. Ralston SH, Gallacher SJ, Patel U, Campbell J, Boyle IT. Cancer-associated hypercalcemia: morbidity and mortality. Clinical experience in 126 treated patients. Ann Intern Med. 1990;112(7):499-504.

3. Ralston SH, Coleman R, Fraser WD, Gallagher SJ, Hosking DJ, lqbal JS, et al. Medical management of hypercalcemia. Calcif Tissue Int. 2004; 74(1):1-11.

4. Clines GA, Guise TA. Hypercalcaemia of malignancy and basic research on mechanisms responsible for osteolytic and osteoblastic metastasis to bone. Endocr Relat Cancer. 2005;12(3):549-83.

5. Donovan PJ, Sundac L, Pretorius CJ, d'Emden MC, McLeod DS. Calcitriolmediated hypercalcemia: causes and course in 101 patients. J Clin Endocrinol Metab. 2013;98(10):4023-9.

6. Casanova D, Sarfati E, De Francisco A, Amado JA, Arias M, Dubost C. Secondary hyperparathyroidism: diagnosis of site of recurrence. World J Surg. 1991;15(4):546-9 discussion 9-50.

7. Galindo RJ, Romao I, Valsamis A, Weinerman S, Harris YT. Hypercalcemia of malignancy and colorectal cancer. World J Oncol. 2016;7(1):5-12. 
8. Luh JY, Han ES, Simmons JR, Whitehead RP. Poorly differentiated colon carcinoma with neuroendocrine features presenting with hypercalcemia and cutaneous metastases: case report and review of the literature. Am J Clin Oncol. 2002;25(2):160-3.

9. Little JB. Radiation carcinogenesis. Carcinogenesis. 2000;21(3):397-404.

10. Miousse IR, Ewing LE, Kutanzi KR, Griffin RJ, Koturbash I. DNA methylation in radiation-induced carcinogenesis: experimental evidence and clinical perspectives. Crit Rev Oncog. 2018;23(1-2):1-11.

\section{Publisher's Note}

Springer Nature remains neutral with regard to jurisdictional claims in published maps and institutional affiliations.

Ready to submit your research? Choose BMC and benefit from:

- fast, convenient online submission

- thorough peer review by experienced researchers in your field

- rapid publication on acceptance

- support for research data, including large and complex data types

- gold Open Access which fosters wider collaboration and increased citations

- maximum visibility for your research: over $100 \mathrm{M}$ website views per year

At $\mathrm{BMC}$, research is always in progress.

Learn more biomedcentral.com/submissions 